\title{
Üniversite Öğrencilerinde COVID-19 Korkusunun Yordayıcısı Olarak Belirsizliğe Tahammülsüzlük
}

\author{
Intolerance of Uncertainty as a Predictor of Fear of COVID-19 in University Students
}

\section{Ersoy ÇARKIT ${ }^{1}$}

${ }^{1}$ Araştırma Görevlisi, Nevşehir Hacı Bektaş Veli Üniversitesi, Rehberlik ve Psikolojik Danışmanlık Anabilim Dal1, carkitersoy@nevsehir.edu.tr, (D)0000-0002-9811-9135

Araştırma makalesi/Research Article
Geliş/Received: 2021-05-10 * $\quad$ Kabul/Accepted: 2021-06-23 $\quad * \quad$ Yayın/Published: 2021-07-22

\section{Atıf/ Citation}

Çarkıt, E. (2021). Üniversite öğrencilerinde COVID-19 korkusunun yordayıcı olarak belirsizliğe tahammülsüzlük. Maarif Mektepleri Uluslararası Eğitim Bilimleri Dergisi, 5(1), 33-42.

https://doi.org/10.46762/mamulebd.934997

Çarkıt, E. (2021). Intolerance of uncertainty as a predictor of fear of COVID-19 in university students. Maarif Mektepleri International Journal of Educational Sciences, 5(1), 33-42.

https://doi.org/10.46762/mamulebd.934997

$\ddot{\mathrm{O} z}$

$\mathrm{Bu}$ araştırmanın amacı, üniversite öğrencilerinde belirsizliğe tahammülsüzlüğün COVID-19 korkusunu yordayıcı rolünü incelemektir. Çalışma grubu, 324 kadın (\%76.1) 102 erkek (\%23.9) olmak üzere toplam 426 üniversite öğrencisinden oluşmaktadır. Katılımcıların yaş ortalaması 21.23'tür (standart sapma $=2.99$ ). Bu araştırma nicel araştırma yöntemlerinden ilişkisel tarama modeli ile yürütülmüştür. Araştırmanın verileri COVID-19 Korkusu Ölçeği, Belirsizliğe Tahammülsüzlük Ölçeği ve Demografik Bilgi Formu ile toplanmıştır. Değişkenler arasındaki ilişki Pearson korelasyon analizi, COVID-19 korkusunun yordanması ise çoklu doğrusal regresyon analizi ile değerlendirilmiştir. Araştırma bulguları ileriye yönelik kaygı ve engelleyici kaygı, COVID-19 korkusunu anlamlı ve pozitif yönde yordadığını göstermiştir. Sonuçlar tartışılmış ve öneriler sunulmuştur.

Anahtar Kelimeler: COVID-19 korkusu, belirsizliğe tahammülsüzlük, COVID-19

\section{Abstract}

The purpose of this study is to examine the predictive role of intolerance to uncertainty on COVID-19 fear among university students. The study group consists of a total of 426 university 
students, 324 women (76.1\%) 102 men (23.9\%). The mean age of the participants is 21.23 (standard deviation $=2.99$ ). This research was conducted with the relational scanning model, one of the quantitative research methods. The data of the study were collected using the Fear of COVID-19 Scale, Intolerance to Uncertainty Scale, and the Demographic Information Form. The relationship between variables was evaluated with the Pearson correlation analysis. The prediction of fear of COVID-19 was evaluated with multiple linear regression analysis. According to the study findings, intolerance to uncertainty positively and significantly predicts the fear of COVID-19. Results are discussed and recommendations are presented.

Keywords: Fear of COVID-19, intolerance of uncertainty, COVID-19

\section{Giriş}

2019 yılının sonlarında başlayan ve tüm dünyayı çok kısa sürede etkisi alan Koronavirüs-19 (COVID-19), dünya düzeninde ciddi değişiklilere neden olmuştur. Hâlâ tedavisi bulunamayan COVID-19, dünya genelinde 153.094.318 kişiyi enfekte etmiş, 3.206.339 kişinin ölümüne neden olmuştur (Dünya Sağlık Örgütü, 2021). Sokağa çıkma kısıtlamaları, çalışma düzeninde değişiklikler, eğitim-öğretim süreçlerinin uzaktan yürütülmesi gibi birçok alanda yeni düzenlemelere gidilmiştir. COVID-19 ile gelen yeni uygulamalar ve salgın tehdidi birçok sorunu da getirmiştir. COVID-19 sürecinde insanlar psikolojik ihtiyaçları karşılamakta zorlanmakta ve kısitlamalarla birlikte aile atmosferleri olumsuz etkilenmektedir (Ar1, 2020). Ayrıca COVID-19 tehdidi ile birlikte uzaktan eğitim sürecinde öğrencilerin zihinsel sağlık sorunları, motivasyon eksikliği, öz-disiplin sağlamada güçlük gibi birçok sorun yaşadığı bulunmuştur (Taşçı, 2021). Bununla birlikte COVID-19 salgını insanların hayatını tehdit ettiği gibi psikolojik sağlıkları için de risk oluşturmaktadır.

İnsanların COVID-19'a yakalanma kayg1sı ve korkusu, Ahorsu vd., (2020), Covid-19 korkusu kavramıyla açıklanmaktadır. Yapılan birçok çalışma COVID-19 korkusunun yaşam doyumunu (Gündoğan, 2021; Satıc1, Göçet-Tekin, Deniz ve Satıc1, 2020) ve zihinsel iyi oluşu olumsuz yönde etkilediğini (Satıcı, Sarıçalı, Satıcı ve Griffiths, 2020) göstermiştir. COVID-19 korkusunun umutsuzluğu (Sarıçalı, Satıcı, Satıcı, Göçet-Tekin ve Griffiths, 2020) ve anksiyeteyi artırdığı (Cevher, Altunkaynak ve Gürü, 2021; Özer, Bayoğlu ve Yöntem, 2021; Wang vd., 2020), kendini toparlama gücünü düşürdüğü (Gündoğan, 2021; Haktanır, Seki ve Dilmaç, 2020) bulunmuştur. Ayrıca yapılan meta analiz çalışmasında, COVID-19 korkusu anksiyete, stres, travmatik stres ve uyku bozukluğu gibi zihinsel sağlık problemleriyle ilişkili bulunmuştur (Şimşir, Koç, Seki ve Griffiths, 2021). Araştırma bulgularına dayanarak COVID-19 korkusunun insanların psikolojik iyi oluşları üzerinde olumsuz etkisi olduğu söylenebilir.

COVID-19 salgının ne zaman sona ereceği, salgın için uygun ve tam tedavi yöntemlerinin ne zaman bulunabileceği veya COVID-19 etkilerinin ne kadar daha devam edeceği gibi konular tüm dünyada belirsizlik oluşturmaktadır. Küresel COVID-19 salgını ile ilişkili belirsizliğin oldukça rahatsız edici olduğu söylenebilir. Bu bağlamda belirsizliğe tahammülsüzlük, COVID-19 korkusu ve COVID-19 
korkusunun psikolojik sağlık üzerindeki etkileri için önemli bir faktördür. Çünkü belirsizliğe tahammülsüzlük duygusal bozukluklar için bir risk ve sürdürücü faktördür (Shihata, McEvoy, Mullan ve Carleton, 2016). Bununla birlikte belirsizliğe tahammül, ruhsal iyi oluş ve mutluluğu artırmaktadır (Khodarahimi, Ghadampour ve Karami, 2021). Belirsizliğe tahammülsüzlük, belirsizlik ve etkileri hakkındaki olumsuz inançlardan kaynaklanan, belirsizlik karşısında bilişsel, duygusal ve davranışsal alanlarda olumsuz tepki verme eğilimidir (Buhr ve Dugas, 2009). Belirsizliğe tahammülsüzlük, depresyon ve anksiyete bozukluklarında özellikle odaklanılması gereken bir konudur (Carleton vd., 2012). Yapılan araştırmalarda belirsizliğe tahammülsüzlük obsesif kompulsif kişilik bozukluğu (Wheaton ve Ward, 2020) ve yeme bozukluğu (Sternheim, Fisher, Harrison ve Watling, 2017) ile pozitif ilişkili bulunmuştur. Belirsizliğe tahammülsüzlük narsisizm, psikopatoloji ve makyavelciliği içeren karanlık üçlü kişilik özelliği (Sabouri vd., 2016) ve olumsuz mükemmeliyetçilik ile pozitif ilişkili bulunurken (Williams ve Levinson, 2021), dışa dönüklük ve açıklık kişilik özellikleriyle negatif yönde ilişkili bulunmuştur (Sternheim, Fisher, Harrison ve Watling, 2017). Araştırma bulgularından olumsuz kişilik özelliklerinin belirsizliğe tahammülsüzlükle yakından ilişkili olduğu söylenebilir. Belirsizliğe tahammülsüzlük yalnızlık ile (Parlapani vd., 2020), olumsuz inançlar (Kıvanç ve Karataş, 2018), umutsuzluk (Kıran, Bozkur ve Cengiz, 2020) ile pozitif, bilişsel esneklik (Bayram, Özkamalı ve Çiftçi, 2021) ile negatif ilişkili bulunmuştur. Ek olarak belirsizliğe tahammülsüzlük ruminasyonu artırmakta (Arbona, Fan, Phang, Olvera ve Dios, 2021; Satıcı, Sarıçalı, Satıcı ve Griffiths, 2020), yaşam doyumu ve iyi oluşu azaltmaktadır (Geçgin ve Sahranç, 2017; Wheaton ve Ward, 2020).

Üniversite öğrencileri üzerinde yapılan bir araştırmada belirsizliğe tahammülsüzlük ile COVID-19 korkusu arasında pozitif ilişki bulunmuştur (Duman, 2020). Bu araştırmada COVID-19 korkusu belirsizliğe tahammülsüzlüğü yordamaktadır (Duman, 2020). Belirsizliğe tahammülsüzlük, belirsizlik durumlarında bilişsel, duygusal ve davranışsal tepki verme eğilimini ifade etmektedir. İnsanlar gelecekteki tehdidi tamamen anlamak ve bir miktar kontrol sahibi olmak isterler (Satıcı vd., 2020). Bu nedenle bu araştırmada COVID-19 salgını ve bu salgının gelece yaratacağı etkiler ile ilgili belirsizlik, COVID-19 korkusunu artıran önemli bir faktör olarak düşünülmektedir. Ayrıca, Duman'ın (2020) araştırmasına sadece 100 üniversite öğrencisi katılmıştır. Bu nedenle daha fazla katılımcının olduğu bir çalışma grubuna ihtiyaç duyulduğu düşünülmektedir. Dolayısıyla bu araştırmanın amacı, üniversite öğrencilerinde belirsizliğe tahammülsüzlüğün COVID-19 korkusunu yordayıp yordamadığını incelemektir. Araştırma bulgularına dayanarak belirsizliğe tahammülsüzlügün COVID-19 korkusunu pozitif yönde yordayacağı düşünülmektedir. Bu araştırma bulgularından COVID-19 korkusunu azaltmaya yönelik müdahale programlarının hazırlanmasında yararlanılabileceği gibi pandemi sürecinde ruh sağllğı hizmeti veren uygulayıcılar tarafından da yararlanılabileceği düşünülmektedir. 


\section{Yöntem}

$\mathrm{Bu}$ araştırma, nicel araştırma yöntemlerinde ilişkisel tarama modeline göre yürütülmüştür. İlişkisel tarama modeli, en az iki değişken arasındaki birlikte değişimi incelemeyi amaçlayan tarama modelidir (Karasar, 2011). Bu araştırmada COVID-19 korkusu ile ileriye yönelik kaygı ve engelleyici kaygı değişkenleri arasındaki birlikte değişim incelenmektedir.

\section{Çalışma Grubu}

Araştırmanın çalışma grubu rastgele seçilen 426 (324 kadın - \%76.1; 102 erkek \%23.9) üniversite öğrencisinden oluşmaktadır. Çalışma grubu ölçme araçlarını web tabanlı uygulama ile cevaplamıştır. Çalışma grubunun yaşı 18-54 arasında değişmektedir (Ortalama $=21.23$, standart sapma $=2.99$ ). Çalı̧̧ma grubunun 247 'si 1.sınıf (\%58), 77'si 2.sınıf (\%18.1), 59'u 3.sinif (\%13.8) ve 43'ü 4.sınıf (\%10.1) üniversite öğrencisidir. Çalışma grubunun 64'ü (\%15) COVID-19'a yakalandığını, 362'si (\%85) yakalanmadığını belirtmiştir. Çalışma grubunun 328'i (\%77) akrabalarından COVID19'a yakalananlar olduğunu, 98'i (\%23) olmadığını belirtmiş̧ir. Çalışma grubunun 95'i (\%22.3) COVID-19 nedeniyle yakınlarından hayatını kaybedenler olduğunu belirtmiştir. Çalışma grubunun 31'i (\%7.3) kronik bir rahatsızlığa sahip olduğunu belirtmiştir.

\section{Veri Toplama Araçları}

\section{COVID-19 korkusu ölçeği}

Katılımcıların COVID-19 korkusu, Ahorsu vd.,'nin (2020) geliştirdiği 7 maddeli COVID-19 Korkusu Ölçeği ile ölçülmüştür. Ölçek maddelerine verilen cevaplar tamamen katılmıyorum ile tamamen katılıyorum aralığında değişen 5'li dereceleme üzerinden verilmektedir. Ölçeğin Türkçe versiyonu psikometrik özellikleri Satıcı, Göçet-Tekin, Deniz ve Satıcı (2020) tarafından yapılmıştır. Türkçe Covid-19 Korkusu Ölçeği yüksek iç tutarlılı̆ga sahiptir $(\alpha=.84)$. Bu araştırmada Türkçe COVID-19 Korkusu Ölçeğinin Cronbach Alfa iç tutarlılık katsayısı .88 bulunmuştur.

\section{Belirsizliğe tahammülsüzlük ölçeği-kısa formu}

Katılımcıların belirsizliğe tahammülsüzlükleri, Belirsizliğe Tahammülsüzlük Ölçeği-Kısa Formu (IUS-12; Carleton, Norton ve Asmundson, 2007) ile ölçülmüştür. 12 maddeden oluşan Belirsizliğe Tahammülsüzlük Ölçeği-Kısa Formu, 5'li derecelemeli likert tipindedir. Ölçeğin iki alt ölçeği bulunmaktadır (ileriye yönelik kayg1 ve engelleyici kaygı). Ölçeğin Türkçe versiyonu geçerlik ve güvenirlik çalışmaları Sarıçam, Erguvan, Akın ve Akça (2014) tarafından yapılmıştır. Belirsizliğe Tahammülsüzlük Ölçeği-Kısa Formu yüksek iç tutarlılığa sahiptir $(\alpha=.88)$. Bu araştırmada Türkçe Belirsizliğe Tahammülsüzlük Ölçeği Kısa Formunun Cronbach Alfa iç tutarlılık katsayısı ileriye yönelik kaygı alt ölçeği için .79, engelleyici kaygı alt ölçeği için .87 bulunmuştur. 


\section{Verilerin Analizi, Geçerlik ve Güvenirlik}

Veriler, R programında R Commender paketi (Fox, 2005, 2017) ile analiz edilmiştir. Pearson Momentler Çarpım Korelasyonu ve çoklu doğrusal regresyon analizi ile veriler analiz edilmiştir. Verileri analiz etmeden önce veriler analizlere hazırlanmış ve regresyon analizi varsayımları kontrol edilmiştir. Başlangıçta eksik veri olup olmadığ incelenmiştir. Veriler online toplandığı için veri setinde eksik değer bulunmamıştır. Aykırı değerlerin olup olmadığı incelenmiştir. Mahalanobis uzaklık testi ile bir katılımcıya ait verilerin aykırı değer olduğu bulunmuş ve bu katılımcıya ait veriler veri setinden silinmiştir. Analizlere 426 katılımcıdan toplanan veriler ile devam edilmiştir. Normal dağılım varsayımının ihlal edilip edilmediği değişkenlerin çarpıklık ve basıklık değerleri (Tablo 1) hesaplanarak incelenmiştir. Çarpıklık ve basıklık değerleri \pm 1.5 arasında olduğu için normal dağılım varsayımı ihlal edilmemektedir (Tabachnick ve Fidell, 2013). Çoklu doğrusallık varsayımı, varyans şişirme faktörü (Variance Inflation Factors; VIF) değeri kontrol edilerek test edilmiştir. Modelin varyans şişirme değeri 1.629 bulunmuştur. Varyans şişirme değeri, 10'dan küçük olduğu için çoklu doğrusallık varsayımı karşılanmaktadır. Son olarak oto korelasyon (öz ilişki) riski Durbin Watson katsayısı hesaplanarak incelenmiştir. Durbin Watsaon katsayısı 1.902 bulunmuştur. Durbin-Watson katsayısı 2'ye yakın olduğu için hata terimleri arasında oto korelasyon (öz ilişki) riski bulunmamaktadır (Gamgam ve Altunkaynak, 2017). Araştırma değişkenlerinin güvenirliklerini belirlemek için Cronbach Alfa iç tutarlılık katsayıları hesaplanmışırı (Tablo 1). Araştırma değişkenlerinin Cronbach Alfa iç tutarlılık katsayıları .79 ile .88 aralığında değişmektedir. Bu değerler, araştırma değişkenlerinin yüksek iç tutarlılığa sahip olduğunu göstermektedir (Nunnally ve Bernstein, 1994).

\section{Bulgular}

Araştırmanın değişkenlerine ilişkin betimsel istatistik, Cronbach alfa iç tutarlılık katsayıları ve değişkenler arası ilişki katsayıları Tablo 1'de sunulmuştur.

Tablo 1. Değişkenler arasındaki ilişki katsayıları ve tanılayıcı istatistik

\begin{tabular}{lccccc}
\hline & 1 & 2 & 3 & Ortalama & Standart sapma \\
\hline 1. COVID-19 korkusu & .88 & .355 & .362 & 17.43 & 6.62 \\
2. Engelleyici kaygı & & .87 & .630 & 16.40 & 5.04 \\
3. İleriye yönelik kayg1 & & & .79 & 25.03 & 5.47 \\
Çarpıklık & .529 & -.154 & -.520 & & \\
Basıklık & -.284 & -.732 & -.030 & &
\end{tabular}

Not: $N=426$. Bütün ilişkiler $p<.01$ düzeyinde anlamlıdır. Köşegendeki sayılar Cronbach Alfa iç tutarlılık katsayısıdır. 
Tablo 1'e göre COVID-19 korkusu, engelleyici kayg1 $(r=.35, p<.01)$ ve ileriye yönelik kaygı $(r=.36, p<.01)$ ile pozitif yönde anlamlı olarak ilişkilidir.

COVID-19 korkusunun belirsizliğe tahammülsüzlük tarafından yordanmasına ilişkin çoklu doğrusal regresyon analizi sonuçları Tablo 2' de sunulmuştur.

Tablo 2. COVID-19 korkusunun yordanmasına ilişkin çoklu regresyon analizi

\begin{tabular}{lllll}
\hline & $\beta$ & Standart hata & $\mathrm{t}$ & $\mathrm{p}$ \\
\hline Sabit & 5.921 & 1.389 & 4.261 & .000 \\
İleriye yönelik kayg1 & .278 & .069 & 4.005 & .000 \\
Engelleyici kayg1 & .276 & .075 & 3.665 & .000 \\
\hline
\end{tabular}

Not: $N=426 ; F=39.81 ; R^{2}=.158 ; \Delta R^{2}=.154 ; p<.001$

İleriye yönelik kaygı ve engelleyici kaygının COVID-19 korkusunu yordayıp yordayamayacağını test etmek için tüm değişkenler eş zamanlı olarak analize girilerek çoklu doğrusal regresyon analizi yapılmıştır. Regresyon analizi sonuçları Tablo 2'de gösterilmiştir. Sonuçlar, regresyon modelinin istatistiksel olarak anlamlı olduğunu ( $F=39.81, p<.001)$ göstermiştir. İleriye yönelik kayg1 ve engelleyici kayg1 birlikte COVID-19 korkusuna ilişkin toplam varyansın \%15'ini açılamaktadır. İleriye yönelik kayg1 $(\beta=.278, p<.001)$ ve engelleyici kayg1 $(\beta=.276, p<.001)$, COVID-19 korkusunun pozitif yönde istatistiksel olarak anlamlı bir şekilde yordamaktadır.

\section{Sonuç ve Tartışma}

$\mathrm{Bu}$ araştırmada, üniversite öğrencilerinde COVID-19 korkusunu belirsizliğe tahammülsüzlüğün yordayıp yordamadığını incelemek amaçlanmıştır. Araştırma bulguları, ileriye yönelik kaygı ve engelleyici kaygının, COVID-19 korkusunu anlamlı ve pozitif yönde yordadığını göstermiştir. Bu bulguya göre belirsizliğe tahammülsüzlük düzeyi yüksek olan üniversite öğrencilerinin daha fazla COVID-19 korkusu yaşadığı söylenebilir. Diğer bir ifade ile belirsizlik durumlarında gelecek kaygısı yaşama eğiliminin artması ve belirsizliğin yarattı̆̆ı kaygıdan dolayı harekete geçememe COVID-19 korkusunu artırmaktadır. Bu araştırmanın sonuçları belirsizliğe tahammülsüzlüğün COVID-19 korkusunu artıracağını bulan önceki araştırma bulguları (Deniz, 2021; Pak, Süsen, Nazlıgül ve Griffiths, 2021; Satıcı vd., 2020) ile tutarlıdır. Çünkü belirsizliğe tahammülsüzlüğü yüksek olan bireylerde belirsizlik, tehdit edici olarak yorumlanır ve sonuçta artan bir duygusal uyarılma yaşanır (Greco ve Roger, 2003). Belirsizliğe tahammülü olmayan kişiler için, belirsiz sonuçları olan durumların, yüksek düzeyde bir kaygı uyandırması ve sürdürmesi muhtemeldir (Dugas, Gosselin ve Ladouceur, 2001). Ayrıca belirsizliğe tahammülsüzlük, olumsuz duyguların oluşumunu ve sürdürülmesini sağlar (Carleton, Collimore ve Asmundson, 2010; Chen ve Lovibond, 2016). Belirsizliğe tahammülsüzlüğün bilinmeyenin altında yatan korkuyu temsil ettiği (Carleton, 2016) 
düşünüldügünde belirsizliğe tahammülü az olan üniversite öğrencilerinin daha fazla COVID-19 korkusu yaşayacağ1 söylenebilir.

$\mathrm{Bu}$ araştırmanın değerli sonuçlarına rağmen dikkate alınması gereken sınırlılıkları bulunmaktadır. Bu araştırmada belirsizliğe tahammülsüzlük ve COVID19 korkusu arasındaki yordayıcı ilişki incelenmiştir. Gelecek araştırmalarda belirsizliğe tahammülsüzlük ve COVID-19 korkusu arasındaki ilişkiyi açıklayabilecek aracı değişkenler incelenebilir. Araştırma sonuçlarının genellenebilirliğini artırmak için farklı gelişim dönemindeki bireylerde araştırma tekrar edilebilir. Gelecekteki araştırmalarda bu iki değişken arasında nedensel çıkarımlar sağlayabilmek için boylamsal ve deneysel araştırma modelleri kullanılabilir. Araştırma bulgularına dayanarak üniversite öğrencilerinin belirsizliğe tahammül düzeyini artırmaya yönelik grupla veya bireysel müdahale programları geliştirilmesi ve uygulanması önerilebilir. Ek olarak belirsizliğe tahammülsüzlüğü azaltmaya yönelik daha önceden etkili olduğu kanitlanan müdahale programları uygulanabilir.

\section{Etik Beyan}

“Üniversite Öğrencilerinde COVID-19 Korkusunun Yordayıcısı Olarak Belirsizliğe Tahammülsüzlük" başlıklı çalışmanın yazım sürecinde bilimsel, etik ve alıntı kurallarına uyulmuş; toplanan veriler üzerinde herhangi bir tahrifat yapılmamış ve bu çalışma herhangi başka bir akademik yayın ortamına değerlendirme için gönderilmemiştir.

\section{Kaynaklar}

Ahorsu, D. K., Lin, C. Y., Imani, V., Saffari, M., Griffiths, M. D., \& Pakpour, A. H. (2020). The fear of covid-19 scale: Development and initial validation. International Journal of Mental Health and Addiction, 1-9. https://doi.org/10.1007/s11469-020-00270-8

Arbona, C., Fan, W., Phang, A., Olvera, N., \& Dios, M. (2021). intolerance of uncertainty, anxiety, and career indecision: A mediation model. Journal of Career Assessment, https://doi.org/10.1177/10690727211002564

Arl, F. A. (2020). Adolescents' psychological needs and perceived family atmosphere during the Covid-19 epidemic process. Turkish Psychological Counseling and Guidance Journal, 10(59), 565-579.

Bayram, F., Özkamalı, E., \& Çiftçi, S. (2021). Tercih sürecindeki üniversite adaylarının belirsizliğe tahammülsüzlük ve bilişsel esneklik düzeyleri arasındaki ilişkinin incelenmesi. Elektronik Sosyal Bilimler Dergisi, 20(77), 98-120.

Buhr, K., \& Dugas, M. J. (2009). The role of fear of anxiety and intolerance of uncertainty in worry: An experimental manipulation. Behaviour Research and Therapy, 47(3), 215223. https://doi.org/10.1016/j.brat.2008.12.004 
Cevher, C., Altunkaynak, B., ve Gürü, M. (2021). Impacts of covid-19 on agricultural production branches: An investigation of anxiety disorders among farmers. Sustainability, 13(9), 1-18. https://doi.org/10.3390/su13095186

Carleton, R. N. (2016). Fear of the unknown: One fear to rule them all? Journal of Anxiety Disorders, 40, 5-21. https://doi.org/10.1016/j.janxdis.2016.03.011

Carleton, R. N., Collimore, K. C., \& Asmundson, G. J. G. (2010). It's not just the judgements it's that I don't know: Intolerance of uncertainty as a predictor of social anxiety. Journal of Anxiety Disorders, 189-195. https://doi.org/10.1016/j.janxdis.2009.10.007

Carleton, R. N., Mulvogue, M. K., Thibodeau, M. A., McCabe, R. E., Antony, M. M., \& Asmundson, G. J. (2012). Increasingly certain about uncertainty: Intolerance of uncertainty across anxiety and depression. Journal of Anxiety Disorders, 26(3), 468479. https://doi.org/10.1016/j.janxdis.2012.01.011

Carleton, R. N., Norton, M. P. J., \& Asmundson, G. J. (2007). Fearing the unknown: A short version of the Intolerance of Uncertainty Scale. Journal of Anxiety Disorders, 21(1), 105-117. https://doi.org/10.1016/j.janxdis.2006.03.014

Chen, J. T. H., \& Lovibond, P. F. (2016). Intolerance of uncertainty is associated with increased threat appraisal and negative affect under ambiguity but not uncertainty. Behavior Therapy, 47(1), 42-53.

Deniz, M. E. (2021). Self-compassion, intolerance of uncertainty, fear of covid-19, and wellbeing: A serial mediation investigation. Personality and Individual Differences, 177, https://doi.org/10.1016/j.paid.2021.110824

Dugas, M. J., Freeston, M. H. ve Ladouceur, R. (1997). Intolerance of uncertainty and problem orientation in worry. Cognitive Therapy and Research, 21(6), 593-606.

Dugas, M. J., Gosselin, P., \& Ladouceur, R. (2001). Intolerance of uncertainty and worry: Investigating specificity in a nonclinical sample. Cognitive Therapy and Research, $25,551-558$.

Duman, N. (2020). Üniversite öğrencilerinde COVID-19 korkusu ve belirsizliğe tahammülsüzlük. The Journal of Social Science, 4(8), 426-437.

Dünya Sağlık Örgütü (2021). WHO coronavirus (covid-19) dashboard. https://covid19.who.int/ adresinden 04.05.2021 tarihinde erişilmiştir.

Fox, J. (2005). The R Commander: A basic statistics graphical user interface to R. Journal of Statistical Software, 14(9), 1-42.

Fox, J. (2017). Using the R Commander: A point-and-click interface for R. Chapman and Hall/CRC Press.

Gamgam, H., \& Altunkaynak, B. (2017). SPSS uygulamal regresyon analizi: Lojistik regresyon, eğri uydurma, tahmin (2.baskı). Ankara: Seçkin Yayıncilık.

Geçgin, F. M., \& Sahranç, Ü. (2017). Belirsizliğe tahammülsüzlük ile psikolojik iyi oluş arasındaki ilişki. Sakarya University Journal of Education, 7(4), 739-755. 
Greco, V., \& Roger, D. (2003). Uncertainty, stress, and health. Personality \& Individual Differences, 34, 1057-1068.

Gündoğan, S. (2021). The mediator role of the fear of covid-19 in the relationship between psychological resilience and life satisfaction. Current Psychology, 1-9. https://doi.org/10.1007/s12144-021-01525-w

Haktanır, A., Seki, T., \& Dilmaç, B. (2020). Adaptation and evaluation of Turkish version of the fear of covid-19 scale. Death Studies, 1-9. https://doi.org/10.1080/07481187.2020.1773026

Karasar, N. (2011). Bilimsel araştırma yöntemleri. Ankara: Nobel Yayınları.

Khodarahimi, S., Ghadampour, E., \& Karami, A. (2021). The roles of spiritual well-being and tolerance of uncertainty in prediction of happiness in elderly. Annals of Psychology, 37(2), 371-377. https://doi.org/10.6018/analesps.446871

Kıran, B., Bozkur, B., \& Cengiz, Ö. (2020). Üniversite öğrencilerinin umutsuzluk düzeyleri, belirsizliğe tahammülsüzlük ve öz yeterliklerinin incelenmesi. Kastamonu Ĕ̆itim Dergisi, 28(6), 2401-2409.

Kıvanç, U., \& Karataş, Z. (2018). Belirsizliğe tahammülsüzlüğün yordayıcısı olarak endişe ile ilgili olumlu ve olumsuz inançlar. Kastamonu Eğitim Dergisi, 26(4), 1267-1276.

Nunnally J., \& Bernstein I. (1994). Psychometric theory. McGraw Hill, New York.

Özer, Ö., Bayoğlu, F., \& Yöntem, M. K. (2021). Validity and reliability study of the Turkish version of the Coronavirus Anxiety Scale. IV. International Conference on Covid-19 Studies, İstanbul, Turkey, 17-19 April 2021.

Pak, H., Süsen, Y., Nazlıgül, M. D., \& Griffiths, M. (2021). The mediating effects of fear of covid-19 and depression on the association between intolerance of uncertainty and emotional eating during the covid-19 pandemic in Turkey. International Journal of Mental Health and Addiction, 1-15. https://doi.org/10.1007/s11469-021$\underline{00489-\mathrm{Z}}$

Parlapani, E., Holeva, V., Nikopoulou, V. A., Sereslis, K., Athanasiadou, M., Godosidis, A., ... \& Diakogiannis, I. (2020). Intolerance of uncertainty and loneliness in older adults during the covid-19 pandemic. Frontiers in Psychiatry, 11, 1-12. https://doi.org/10.3389/fpsyt.2020.00842

Sabouri, S., Gerber, M., Lemola, S., Becker, S. P., Shamsi, M., Shakouri, Z., ... \& Brand, S. (2016). Examining Dark Triad traits in relation to sleep disturbances, anxiety sensitivity and intolerance of uncertainty in young adults. Comprehensive Psychiatry, 68, 103-110. https://doi.org/10.1016/j.comppsych.2016.03.012

Sarıçalı, M., Satıcı, S. A., Satıcı, B., Göçet-Tekin, E., \& Griffiths, M. D. (2020). Fear of covid-19, mindfulness, humor, and hopelessness: A multiple mediation analysis. International Journal of Mental Health and Addiction, 1-14. https://doi.org/10.1007/s11469-020-00419-5

Sarıçam, H., Erguvan, F. M., Akın, A., \& Akça, M. Ş. (2014). The Turkish short version of the intolerance of uncertainty (IUS-12) scale: The study of validity and reliability. Route Educational and Social Science Journal, 1(3), 148-157. 
Satıcı, B., Göçet-Tekin, E., Deniz, M. E., \& Satıcı, S. A. (2020). Adaptation of the fear of covid19 scale: Its association with psychological distress and life satisfaction in Turkey. International Journal of Mental Health and Addiction, 1-9. https://doi.org/10.1007/s11469-020-00294-0

Satıcı, B., Sarıçalı, M., Satıcı, S. A., \& Griffiths, M. D. (2020). Intolerance of uncertainty and mental wellbeing: Serial mediation by rumination and fear of covid19. International Journal of Mental Health and Addiction, 1-12. https://doi.org/10.1007/s11469-020-00305-0

Shihata, S., McEvoy, P. M., Mullan, B. A., \& Carleton, R. N. (2016). Intolerance of uncertainty in emotional disorders: What uncertainties remain? Journal of Anxiety Disorders, 41, 115-124. https://doi.org/10.1016/j.janxdis.2016.05.001

Sternheim, L. C., Fisher, M., Harrison, A., \& Watling, R. (2017). Predicting intolerance of uncertainty in individuals with eating disorder symptoms. Journal of Eating Disorders, 5(26), 1-9. https://doi.org/10.1186/s40337-017-0152-4

Şimşir, Z., Koç, H., Seki, T., \& Griffiths, M. D. (2021). The relationship between fear of covid19 and mental health problems: A meta-analysis. Death Studies, 1-9. https://doi.org/10.1080/07481187.2021.1889097

Tabachnick, B. G., \& Fidell, L. S. (2013). Using multivariate statistics. Pearson Education.

Taşçı, S. (2021). Evaluation of emergency distance language education: Perspectives of ELT students. Nevşehir Hacı Bektaş Veli Üniversitesi Sosyal Bilimler Enstitüsü Dergisi, 11(1), 286-300.

Wang, C., Pan, R., Wan, X., Tan, Y., Xu, L., Ho, C. S. ve Ho, R.C. (2020). Immediate psychological responses and associated factors during the initial stage of the 2019 coronavirus disease (covid-19) epidemic among the general population in China. International Journal of Environmental Research and Public Health, 17, 1-25. https://doi.org/10.3390/ijerph17051729

Wheaton, M. G., \& Ward, H. E. (2020). Intolerance of uncertainty and obsessive-compulsive personality disorder. Personality Disorders: Theory, Research, and Treatment, 11(5), 357-364. https://doi.org/10.1037/per0000396

Williams, B. M., \& Levinson, C. A. (2021). Intolerance of uncertainty and maladaptive perfectionism as maintenance factors for eating disorders and obsessivecompulsive disorder symptoms. European Eating Disorders Review, 29(1), 101-111. https://doi.org/10.1002/erv.2807 